\title{
ANALISIS KORELASI PERUBAHAN TUTUPAN VEGETASI TERHADAP PERUBAHAN SUHU UDARA DI KOTA DENPASAR
}

\author{
Mar'ie Abda'u Zal ${ }^{1)}$, I Wayan Nuarsa ${ }^{\left.2^{*}\right)}$, Ni Wayan Febriana Utami ${ }^{1)}$ \\ ${ }^{1)}$ Program Studi Arsitektur Pertamanan, Fakultas Pertanian, Universitas Udayana \\ ${ }^{2)}$ Program Studi Agroekoteknologi, Fakultas Pertanian, Universitas Udayana \\ *E-mail:nuarsa@gmail.com
}

\section{ABSTRACT \\ CORRELATION ANALYSIS OF VEGETATION COVERAGE CHANGE ON AIR TEMPERATURE CHANGE IN DENPASAR CITY}

The rate of growth and development of Denpasar city increases the demand for land to supply the needs of urban facilities and infrastructure. This affected to the increase of conversion of vegetation coverage into built-up land cover. The conversion of the vegetation coverage impacts on urban environmental quality which is increase the rate of air temperature. The purpose of this study is to examine the impact of vegetation coverage change on the air temperature change in Denpasar cityin year of 2003, 2009 and 2015. Remote sensing and regression statistic method were used in this study. The results showed that the decrease of vegetation coverage influenced the increase of air temperature in Denpasar city. Statistically, the correlation can be projected on the equation $y=31,295-0,078 x$, where $\mathrm{x}$ and $\mathrm{y}$ are vegetaton coverege and air temperature respectively. This equation shows that decresing of $1 \%$ vegetation coverege will increase $0,078^{\circ} \mathrm{C}$ of air temperature. The effort to conceder in responding to the temperature rise that occurred in Denpasar is increasing the number of green open space. Based on the classification value of vegetation coverage and air temperature of Denpasar City, there are three categories of priority areas for green open space development that is high, medium and low priority. The development of green open space in each priority area can be adjusted to the characteristics of land use.

Keywords: vegetation coverage, land cover, air temperature, remote sensing

\section{PENDAHULUAN}

Pemerintah Indonesia melalui Rencana Tata Ruang dan Wilayah pada Peraturan Presiden No. 45 Tahun 2011 berencana menjadikan Kota Denpasar sebagai salah satu kota metropolitan baru di Indonesia. Kebijakan ini tentu saja akan mempengaruhi laju pertumbuhan dan perkembangan kota. Meningkatnya laju tersebut mempengaruhi tingginya kebutuhan lahan, sehingga alih fungsi lahantidak dapat dihindari lagi. Lahan yang awalnya merupakan tutupan vegetasiberubah menjadi lahan terbangun untuk memenuhi sarana dan prasarana kota.

Dalam beberapa tahun terakhir, tutupan vegetasi Kota Denpasar telah mengalami penurunan. Sepanjang tahun 2008-2015 telah terjadi penurunan lahan sawah sebesar $2,83 \mathrm{~km}^{2}$ menjadi $24,79 \mathrm{~km}^{2}$. Sementara itu, hasil survei yang dilakukanoleh Wijaatmaja (2015), menunjukkan bahwa luas kawasan terbangun Kota Denpasar meningkat mencapai $64 \%$ dari seluruh luas Kota. Menurut Riana et al. (2014) mayoritas alih fungsi lahan di Kota Denpasar adalah untuk memenuhi kebutuhan tempat tinggal yaitu mencapai $94,12 \%$. Penurunan lahan tutupan vegetasi, peningkatan luas lahan terbangun, serta semakin padatnya penduduk memperburuk kualitas lingkungan kota dan paling mudah dirasakan adalah terjadinya peningkatan suhu udara. Rata-rata suhu udara Kota Denpasar meningkat sebesar $0,6^{\circ} \mathrm{C}$ selama tahun $2003-2015$ dan suhu tertingginya telah mencapai $32,8^{\circ} \mathrm{C}$ (BPS, 2003; BPS, 2016).

Perubahan lahan tutupan vegetasi menjadi lahan terbangun merupakan salah satu faktor yang mempengaruhi terjadinya peningkatan suhu. Effendy et al. (2006) mengatakan bahwa perluasan wilayah di sebuah kota yang menyebabkan berkurangnya areal tutupan vegetasi akan mempengaruhi kondisi iklim mikro di wilayah tersebut. Penelitian ini dilakukan untuk mengkaji sejauh mana perubahan tutupan vegetasi mempengaruhi perubahan suhu udara di Kota Denpasar, dengan menggunakan metode pengindraan jauhdan analsis korelasi. Informasi yang dihasilkan diharapkan dapat menjadi bahan pertimbangan dalam penataan dan pengelolaan ruang Kota Denpasar untuk menciptakan lingkungan kota yang nyaman. 


\section{METODOLOGI}

\subsection{Gambaran Umum Kota Denpasar}

Kota Denpasar merupakan ibu kota Provinsi Bali terletak di antara 8 35' 31"- 8 44" 49" LS dan 115 10' $23^{\prime \prime}-115$ 16' 27" BT. Luas wilayahnya yaitu 127,78 $\mathrm{km}^{2}$ yang terdiri dari empat wilayah kecamatan dan 43 desa/kelurahan. Penggunaan lahan Kota Denpasar pada tahun 2015 yaitu sekitar $24,79 \mathrm{~km}^{2}$ merupakan lahan sawah, $5,10 \mathrm{~km}^{2}$ lahan pertanian bukan sawah dan sisanya seluas $97,89 \mathrm{~km}^{2}$ lahan bukan pertanian seperti jalan, permukiman, perkantoran, sungai, dan lain-lain. Kota Denpasar sebagian besar berada pada ketinggian antara $0 \mathrm{~m}$ $25 \mathrm{~m}$ dpl, dan sebesar 41,9\% wilayahnya berada pada $75 \mathrm{~m}$ dpl. Keadaan rata-rata suhu Kota Denpasar yaitu $27,6{ }^{\circ} \mathrm{C}$, kelembaban $73 \%$ dengan rata-rata curah hujan adalah 120,6 mm. Penduduk Kota Denpasar berjumlah 880.600 jiwa yang terdiri dari 449.700 jiwa penduduk laki-laki (51,05\%) dan 430.900 jiwa penduduk perempuan $(48,95)$. Kecamatan Denpasar Selatan dengan penduduk tertinggi yaitu sebesar 279.640 jiwa, diikuti oleh Kecamatan Denpasar Barat 255.160 jiwa, Kecamatan Denpasar Utara 194.600 jiwa dan Kecamatan Denpasar Timur 151.200 jiwa (BPS, 2016).

\subsection{Waktu dan Tempat Penelitian}

Penelitian ini dilaksanakan mulai dari bulan Juni 2016 sampai bulan Mei 2017 di Kota Denpasar. Secara geografis dan administratif, lokasi daerah penelitian disajikan pada Gambar1.

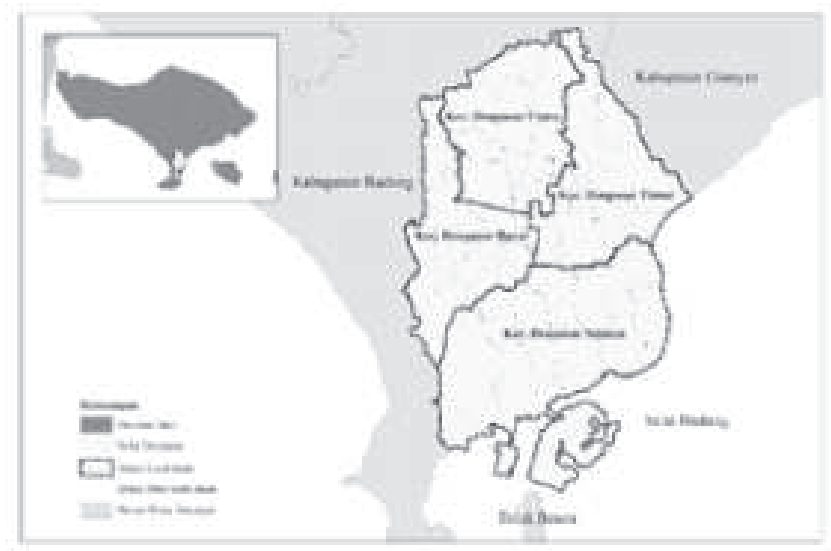

Gambar 1. Lokasi daerah penelitian.

\subsection{Alat dan Bahan Penelitian}

Alat yang digunakan dalam penelitian ini adalah seperangkat komputer yang lengkapi dengan perangkat lunak antara lain: Google Earth, ENVI 5.3 dan ArcGIS 10.3, Microsoft Excel, dan SPPS 2.3. Bahan penelitian adalah citra satelit Landsat 7 ETM+ path/row 116/66 akuisisi 21 Maret 2003, 21 Maret 2009, dan 15 Oktober 2009 (sebagai citra fill untuk gapcitra 21 Maret 2009), Landsat 8 OLI akuisisi 30 Maret 2015, serta Peta Rupabumi Kota Denpasar skala 1:25.000.

\subsection{Metode Penelitian}

Data persentase tutupan vegetasi dan suhu permukaan lahan diperoleh dari hasil analisis data pengindertaan jauh, yaitu Landsat 7 ETM+ dan Landsat 8 OLI.Analisis berikutnya dilanjutkan dengan analisis statistika regresi linier sederhana untuk mengetahui korelasi antara tutupan vegetasi dengan suhu udara tersebut.

Sebelum citra dianalisis dilakukan perbaikan dan beberapa proses koreksi citra untuk menghasilkan citra yang siap dianalisis. Perbaikan citra yaitu dengan proses gap-fill. Proses ini merupakan proses perbaikan citra Landsat 7 ETM+ akuisisi 21 Maret 2009 yang mengalami strip/gap pada hasil pemotretannya akibat kerusakan scan line corrector (SLC). Gap-fill citra dilakukan dengan cara mengambil informasi dari citra yang berbeda waktu perekamannya yakni citra Landsat akuisisi 15 Oktober 2009 agar pixel pada daerah strip/gap dapat diperbaiki.Proses berikutnya adalah pemotongan citra Landsat untuk mendapatkan wilayah kajian sesuai peta administrasi Kota Denpasar.

Nilai persentase tutupan vegetasi didapatkan berdasarkan pengaplikasian persamaan antara nilai NDVI (Normalized Differential Vegetation Indexed) dengan persentase tutupan vegetasi hasil digitasi peta Google Earth. Nilai suhu udaradidapatkan berdasarkan nilai Digital Number (DN) pada kanalkanal citra Landsat yang dikonversi terdahulu menjadi spectral radiance $\left(\mathrm{L}_{\ddot{e}}\right)$. Kemudian, dari $\mathrm{L}_{\text {ë }}$ dapat dikonversi menjadi nilai albedo, radiasi gelombang pendek yang keluar (Rsout) dan gelombang radiasi pendek yang datang (Rsin), radiasi gelombang panjang yang keluar (Rlout) danbrightness temperature $\left(\mathrm{T}_{\mathrm{B}}\right)$. Nilai-nilai tersebut kemudian digunakan untuk mencari nilai suhu permukaan (Ts), radiasi netto $(\mathrm{Rn})$, fluks bahang tanah $(\mathrm{G})$, fluks bahang terasa $(\mathrm{H})$ dan suhu udara (Ta).

\section{HASIL DAN PEMBAHASAN}

\subsection{Analisis Citra}

\subsubsection{Prerosesing Citra}

Sebelum analisis citra dilakukan untuk menentukan tutupan vegetasi dan suhu permukaan lahan perlu dilakukan pra pengolahan citra. Proses ini terdiri dari pengisian citra tanpa nilai piksel (gapfill) dan pemotongan citra (image cropping). Proses gap-fill dapat dilihat pada Gambar 2, sedangkan proses pemotongan citra disajikan pada Gambar 3. 


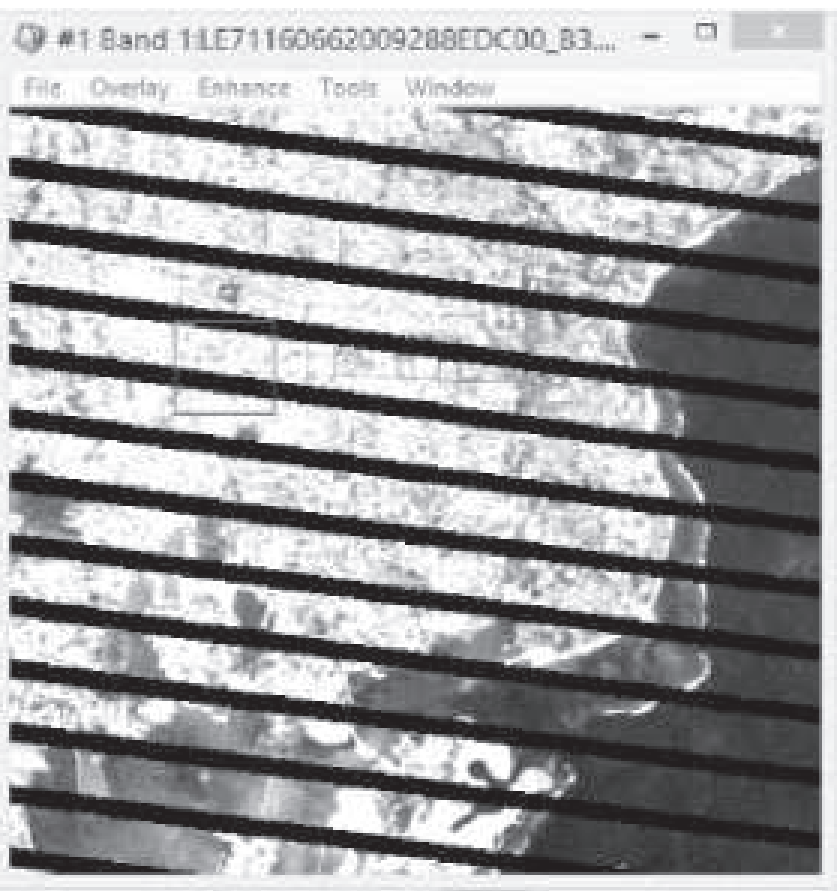

Sebelum

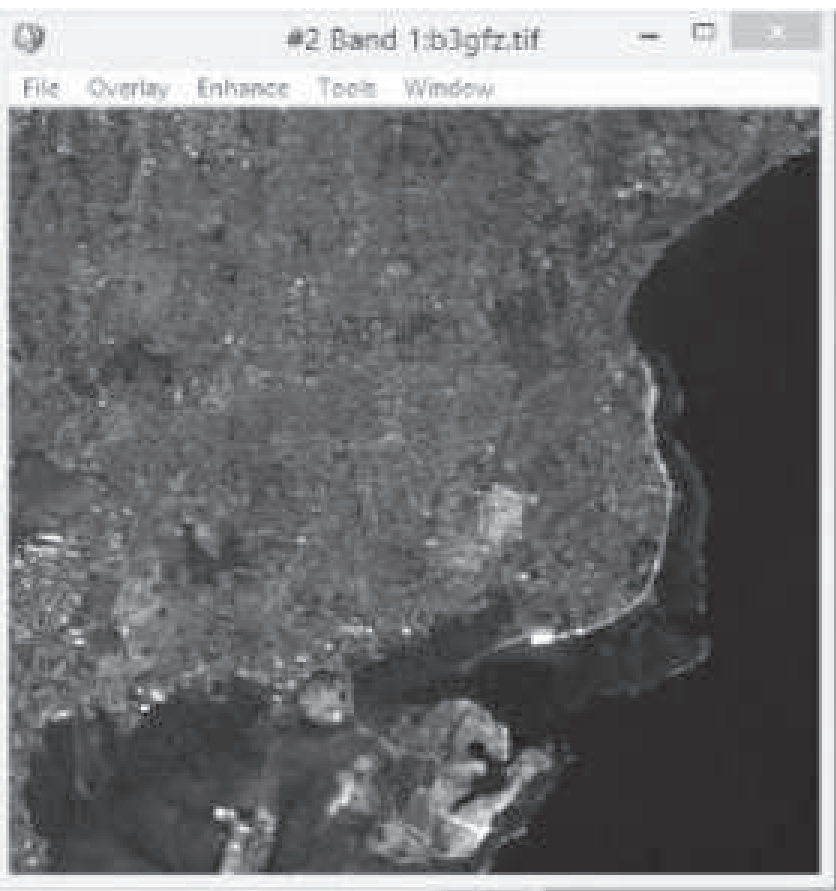

Setelah

Gambar 2. Citra Landsat sebelum dan sesudah Gap-fill

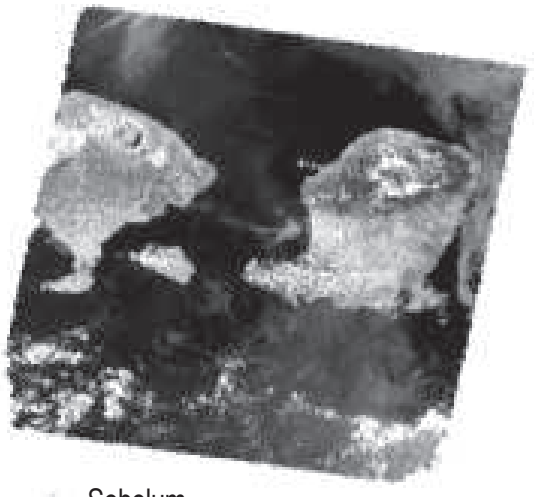

Sebelum

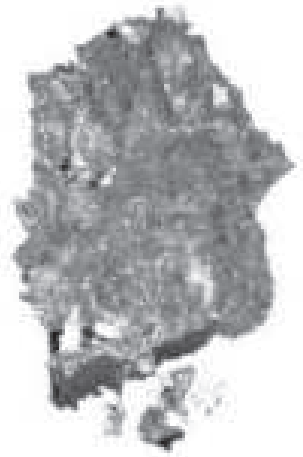

Setelah

Gambar 3. Peta Citra Landsat sebelum dan sesudah Pemotongan

\subsubsection{Indeks Vegetasi}

Indeks vegetasi yang digunakan dalam penentuan persentase tutupan vegetasi adalah NDVI (Normalized Difference Vegetation Index). Berdasarkan hasil pengolahan citra didapatkan bahwa nilai NDVI Kota Denpasar mengalami penurunan dalam beberapa tahun terakhir. Secara rata-rata indeks vegetasi Kota Denpasar pada tahun 2003 adalah 0,27. Pada tahun 2009 terjadi penurunan sebesar 0,1 menjadi 0,26. Kemudian, pada tahun 2015 penurunan terjadi hingga 0,4 menjadi 0,22. Perubahan nilai NDVI Kota Denpasar dalam bentuk histogram ditampilkan pada Gambar 4.

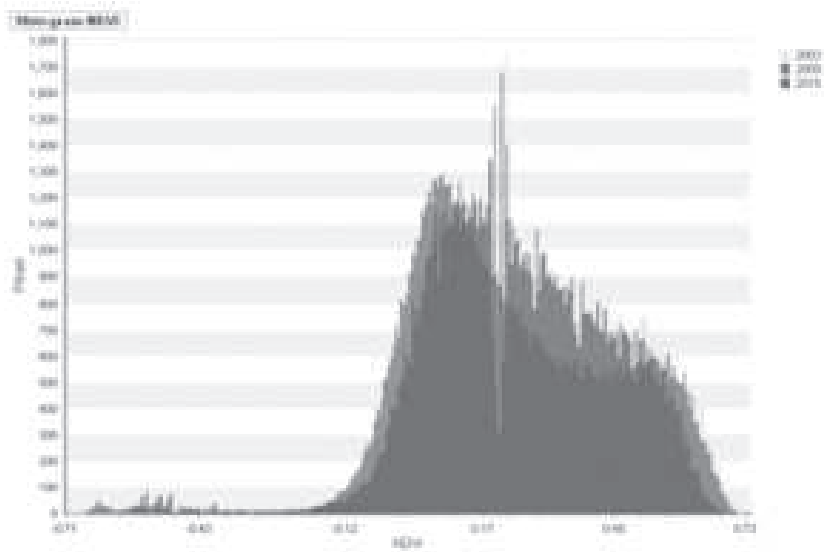

Gambar 4. Histogram NDVI Kota Denpasar Tahun 2003, 2009 dan 2015 


\subsubsection{Estimasi Tutupan Vegetasi Kota Denpasar}

Berdasarkan hasil permodelan grafik scatterplot antara NDVI dan tutupan vegetasi hasil digitasi peta Google Earth diperoleh hubungan linear yaitu $y=1,3453 x-0,0047$, dimana $\mathrm{x}$ dan y masing-masing adalah nilai NDVI dan persentase tutupan vegetasi (Gambar 5). Persamaan ini kemudian diaplikasikan pada nilai NDVI sehingga didapatkan nilai persentase tutupan vegetasi Kota Denpasar.

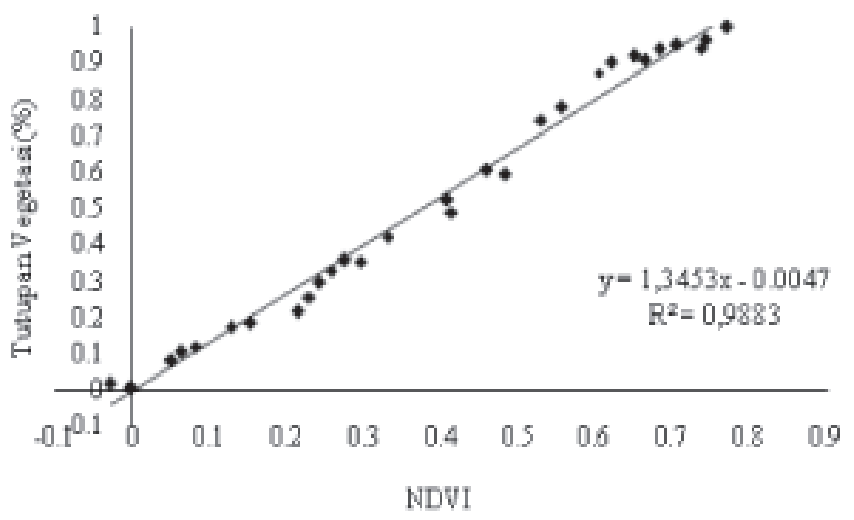

Gambar 5. Scatterplot antara NDVI dan Tutupan Vegetasi
Persentase lahan tutupan vegetasi Kota Denpasar diketahuimengalami penurunan pada tahun 2003, 2009 dan 2015. Rata-rata persentase lahan tutupan vegetasi Kota Denpasar tahun 2003 adalah sebesar $36,05 \%$, menurun menjadi $33,29 \%$ pada tahun 2009 dan menurun kembali menjadi $28,40 \%$ pada tahun 2015 . Perubahan nilai persentase lahan tutupan vegetasi di berbagai wilayah Kota Denpasar dapat dilihat pada Tabel 1. Penurunan terbesar terjadi di Kecamatan Denpasar Barat yakni hingga sebesar 2,72\% dari seluruh luas Kota Denpasar. Perubahan tutupan lahan vegetasi Kota denpasar secara spasial disajikan pada Gambar 6 .

Warna jingga gelap pada peta sebaran tutupan vegetasi mengindikasikan daerah dengan persentase lahan tutupan vegetasi sangat rendah hingga tidak bervegetasi $(<10 \%)$. Warna jingga terang mengindikasikan daerah dengan persentase lahan tutupan vegetasi rendah (10\%-30\%) dan hijau terang mengindikasikan daerah dengan persentase lahan tutupan vegetasi sedang (30\%-50\%). Warna hijau gelap mengindikasikan daerah dengan persentase lahan tutupan vegetasi semakin tinggi $(>50 \%)$.Terlihat bahwa sebaran warna jingga pada ketiga tahun cenderung berada di pusat Kota

Tabel 1. Perubahan Nilai Persentase Tutupan Vegetasi Kota Denpasar

\begin{tabular}{|c|c|c|c|c|c|c|}
\hline \multirow{2}{*}{ Wilayah } & \multicolumn{6}{|c|}{ Tutupan Vegetasi (\%) } \\
\hline & 2003 & $+/-$ & 2009 & $+/-$ & 2015 & $+/-(2003-2015)$ \\
\hline Kec. Denpasar Utara & 8,17 & $-0,37$ & 7,79 & $-1,93$ & 5,86 & $-2,31$ \\
\hline Kec. Denpasar Timur & 8,86 & $-0,71$ & 8,16 & $-0,26$ & 7,90 & $-0,96$ \\
\hline Kec. Denpasar Selatan & 13,33 & $-0,83$ & 12,50 & $-0,84$ & 11,67 & $-1,66$ \\
\hline Kec. Denpasar Barat & 5,69 & $-0,86$ & 4,83 & $-1,87$ & 2,97 & $-2,72$ \\
\hline Rata-rata Kota Denpasar & 36,05 & $-2,76$ & 33,29 & $-4,89$ & 28,40 & $-7,65$ \\
\hline
\end{tabular}

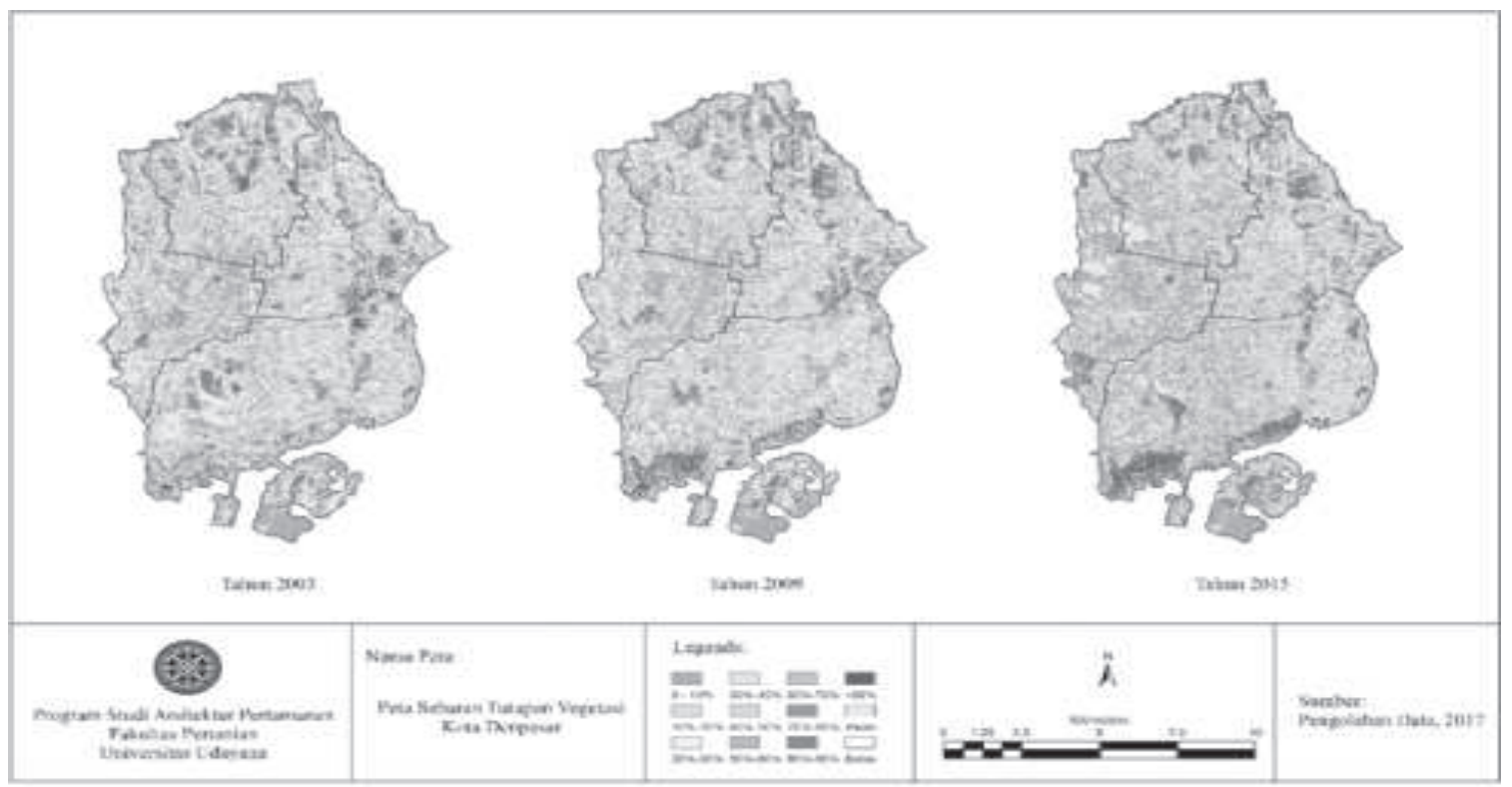

Gambar 6. Peta Sebaran Tutupan Vegetasi Kota Denpasar 
Denpasar, kemudian melebar menuju ke perbatasan melalui segala arah. Pembangunan untuk memenuhi sarana dan prasarana kota tersebut membutuhkan lahan. Akibatnya, alih fungsi lahan terjadi pada lahan tutupan vegetasi menjadi lahan yang didominasi lahan terbangun, sehingga menyebabkansebaran warna hijau semakin berkurang dan memperjelas warna jingga dari tahun ke tahun.

\subsubsection{Estimasi Suhu Udara Kota Denpasar}

Rata-rata suhu udara Kota Denpasar padatahun 2003, 2009 dan 2015 mengalami perubahan yaitu kenaikan sebesar $1,7^{\circ} \mathrm{C}$. Rata-rata suhu udara tahun 2003 ke tahun 2009 mengalami kenaikan sebesar $0,2^{\circ} \mathrm{C}$. Kemudian, pada tahun 2015 mengalami kenaikan kembalisebesar $1,5^{\circ} \mathrm{C}$. Perubahan nilai suhu udara di berbagai wilayah Kota Denpasar disajikan pada pada Tabel 2. Kenaikan suhu tertinggi terjadi di Kecamatan Denpasar Selatan sebesar $1,8^{\circ} \mathrm{C}$, kemudian diikuti oleh Kecamatan Denpasar Timur sebesar $1,7{ }^{\circ} \mathrm{C}$ serta Kecamatan Denpasar Timur dan Kecamatan Denpasar Selatan sebesar 1,5 ${ }^{\circ} \mathrm{C}$. Perubahan suhu Kota Denpasar disajikan dalam bentuk peta spasial pada Gambar 7 .

Warna biru mengindikasikan daerah yang memiliki suhu $<26{ }^{\circ} \mathrm{C}$, warna biru kehijauan bersuhu $26{ }^{\circ} \mathrm{C}-28{ }^{\circ} \mathrm{C}$, warna kuning bersuhu $28{ }^{\circ} \mathrm{C}-30{ }^{\circ} \mathrm{C}$, warna jingga bersuhu $30{ }^{\circ} \mathrm{C}-33^{\circ} \mathrm{C}$ dan warna merah bersuhu $>33^{\circ} \mathrm{C}$. Terlihat pada tahun 2003 sebaran

Tabel 2. Perubahan Nilai Suhu Udara di berbagai Wilayah Kota Denpasar

\begin{tabular}{|c|c|c|c|c|c|c|c|}
\hline Wilayah & Keterangan & $2003\left({ }^{\circ} \mathrm{C}\right)$ & $+1-\left({ }^{\circ} \mathrm{C}\right)$ & $2009\left({ }^{\circ} \mathrm{C}\right)$ & $+1-\left({ }^{\circ} \mathrm{C}\right)$ & $2015\left({ }^{\circ} \mathrm{C}\right)$ & $+/-\left({ }^{\circ} \mathrm{C}\right) 2003-2015$ \\
\hline \multirow[t]{3}{*}{ Kec. Denpasar Utara } & minimum & 20,0 & 1,2 & 21,2 & $-0,7$ & 20,5 & 0,5 \\
\hline & maksimum & 33,8 & $-0,3$ & 33,5 & 0,4 & 33,9 & 0,1 \\
\hline & rata-rata & 26,7 & 0,1 & 26,8 & 1,4 & 28,2 & 1,5 \\
\hline \multirow[t]{3}{*}{ Kec. Denpasar Timur } & minimum & 20,9 & $-0,1$ & 20,8 & 1,5 & 22,4 & 1,5 \\
\hline & maksimum & 34,1 & $-0,2$ & 33,9 & 0,5 & 34,5 & 0,3 \\
\hline & rata-rata & 26,7 & 0,0 & 26,7 & 1,7 & 28,4 & 1,7 \\
\hline \multirow[t]{3}{*}{ Kec. Denpasar Barat } & minimum & 19,8 & 1,7 & 21,5 & $-2,0$ & 19,5 & $-0,3$ \\
\hline & maksimum & 35,2 & $-1,1$ & 34,1 & 0,5 & 34,5 & $-0,6$ \\
\hline & rata-rata & 27,5 & $-0,2$ & 27,3 & 1,7 & 29,0 & 1,5 \\
\hline \multirow[t]{3}{*}{ Kec. Denpasar Selatan } & minimum & 18,7 & 2,6 & 21,3 & $-0,4$ & 20,8 & 2,1 \\
\hline & maksimum & 34,0 & $-0,7$ & 33,3 & 0,5 & 33,9 & $-0,1$ \\
\hline & rata-rata & 26,0 & 0,8 & 26,8 & 1,0 & 27,8 & 1,8 \\
\hline \multirow[t]{3}{*}{ Kota Denpasar } & minimum & 19,8 & 1,4 & 21,2 & $-0,4$ & 20,8 & 1,0 \\
\hline & maksimum & 34,3 & $-0,6$ & 33,7 & 0,5 & 34,2 & $-0,1$ \\
\hline & rata-rata & 26,7 & 0,2 & 26,9 & 1,5 & 28,4 & 1,7 \\
\hline
\end{tabular}

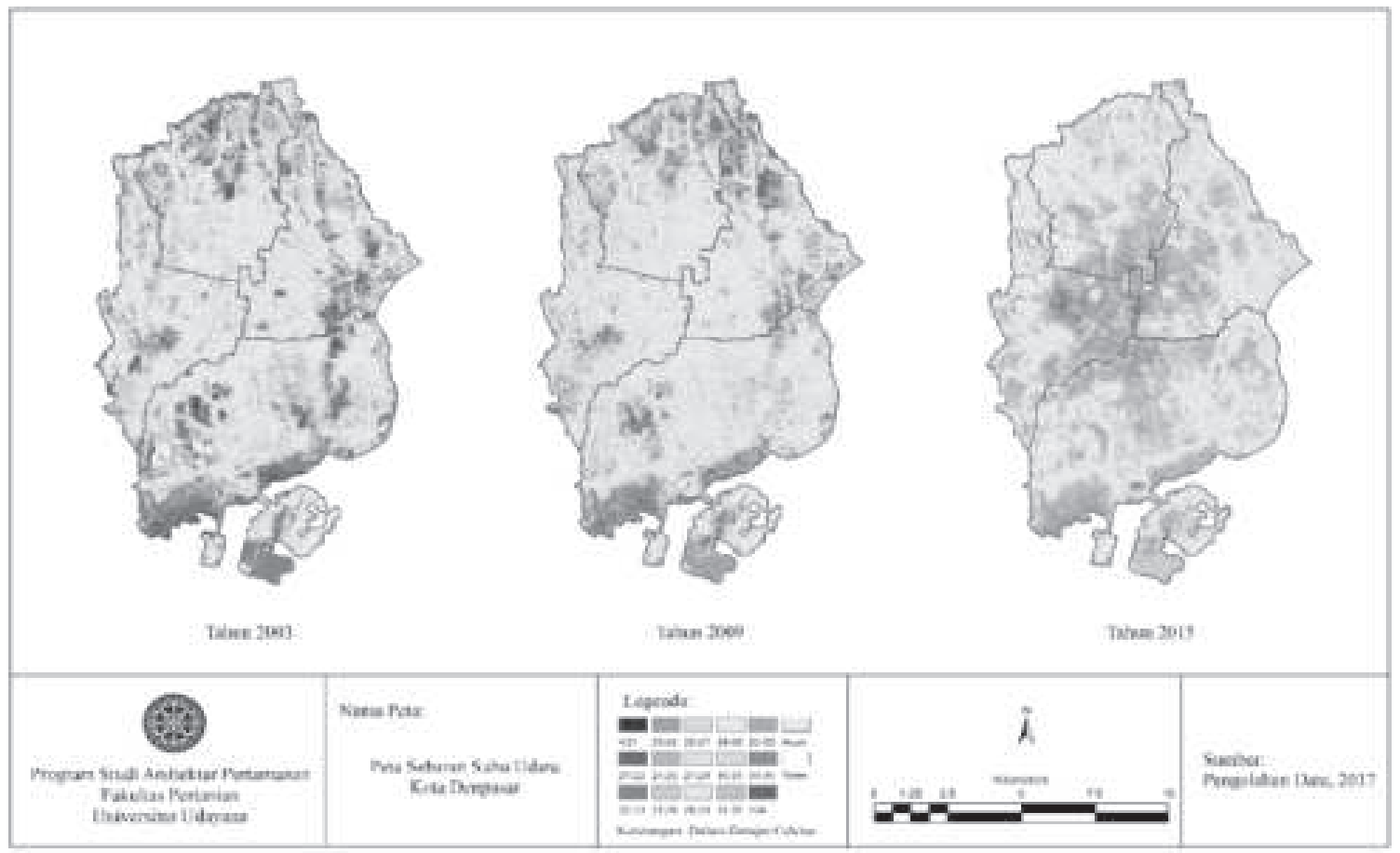

Gambar 7. Peta Sebaran Suhu Udara Kota Denpasar 
suhu udara masih didominasi oleh warna biru, biru kehijauan dan kuning, sedangkan warna jingga dan merah masih terlihat jarang. Pada tahun 2009, warna biru dan biru kehijauan mulai berubah menjadi warna kuning, artinya daerah yang suhu awalnya rendah berubah menjadi lebih tinggi. Kemudian, pada tahun 2015 sebaran warna biru dan biru kehijauan telah semakin terlihat jarang dan berubah menjadi warna kuning, jingga dan merah. Bahkan, warna jingga dan merah terlihat dengan sangat kontras telah mendominasi hampir menutupi di seluruh wilayah kota. Artinya, suhu udara Kota Denpasar pada tahun 2003, 2009 dan 2015 telah mengalami kenaikan yang terjadi hampir di seluruh wilayah Kota Denpasar.

\subsection{Pengaruh Perubahan Tutupan Vegetasi terhadap Suhu Udara}

Pengaruh perubahan nilai tutupan vegetasi terhadap perubahan suhu udara Kota Denpasar dijelaskan secara grafik pada Gambar 8. Gambar tersebut menunjukkan pengaruh setiap perubahan nilai persentase tutupan vegetasiterhadapsuhu udara Kota Denpasar di berbagai variasi penggunaan lahan yang dilalui garis profil A-A' seperti pada Gambar 1 . Grafik tutupan vegetasi menunjukkan arah yang tidak linier atau menunjukkan arah yang berlawanan dengan grafik suhu udara, artinya jika terjadi penurunan persentase tutupan vegetasi maka grafik suhu udara akan mengalami kenaikan. Sebaliknya, jika terjadi kenaikan persentase tutupan vegetasi maka grafik suhu udara akan mengalami penurunan.

\subsection{Analisis Statistika}

Berdasarkan hasil analisis statistika regresi linier sederhana diperoleh bahwa bentuk persamaan terpilih adalah persamaan tahun 2015 karena memiliki nilai $r$ tertinggi yaitu sebesar 0,872 seperti pada Tabel 3. Artinya, korelasi paling kuat terjadi antara perubahan nilai persentase tutupan vegetasi dengan perubahan nilai suhu udara Kota Denpasar yakni pada tahun 2015. Grafik model scatterplot persamaan tersebut disajikan pada Gambar 9. Grafik tersebut menunjukkan arah regresi negatif, artinya setiap penurunan nilai persentase tutupan vegetasi yang terjadi maka akan diikuti oleh kenaikan nilai suhu udara.

Tabel 3. Hasil Analisis Regresi Linier Sederhana

\begin{tabular}{llcccc}
\hline Tahun & Persamaan & $\boldsymbol{r}$ & $\boldsymbol{R}^{2}$ & $t_{0}$ & t $_{\text {aD2 }}$ \\
\hline 2003 & $y=29,294-0,074 x$ & 0,716 & 0,5122 & $-20,392$ & 1,97 \\
2009 & $y=29,547-0,071 x$ & 0,764 & 0,5843 & $-23,594$ & 1,97 \\
2015 & $y=31,295-0.078 x$ & 0,872 & 0,7605 & -35.475 & 1,97 \\
\hline
\end{tabular}

Persamaan terpilih tahun 2015 menunjukkan nilai $R^{2}$ sebesar 0,7605 , artinya adalah bahwa terdapat $76 \%$ variasi dari tutupan vegetasi mempengaruhi suhu udara dan sisanya dipengaruhi oleh faktor lain yang dalam hal ini tidak dijelaskan dalam model. Nilai 31,295, artinya jika tidak ada perubahan luas tutupan vegetasi maka suhu udara berada pada suhu $31,3^{\circ} \mathrm{C}$. Nilai -0,078x merupakan koefisien regresi yang menunjukkan bahwa setiap adanya pengurangan 1\% tutupan vegetasi maka akan terjadi kenaikan suhu udara sebesar 0,078 ${ }^{\circ} \mathrm{C}$.Penarikan kesimpulan berdasarkan uji hipotesis regresi adalah bahwa $\mathrm{H}_{0}$ ditolak karena nilai $\mathrm{t}_{0} \mathrm{~d}$ " $\mathrm{t}_{\text {áD } 2}$ seperti pada Tabel 3, sehingga persamaan $y=$ 31,295-0,078x dapatmengestimasilaju perubahan suhu udara.

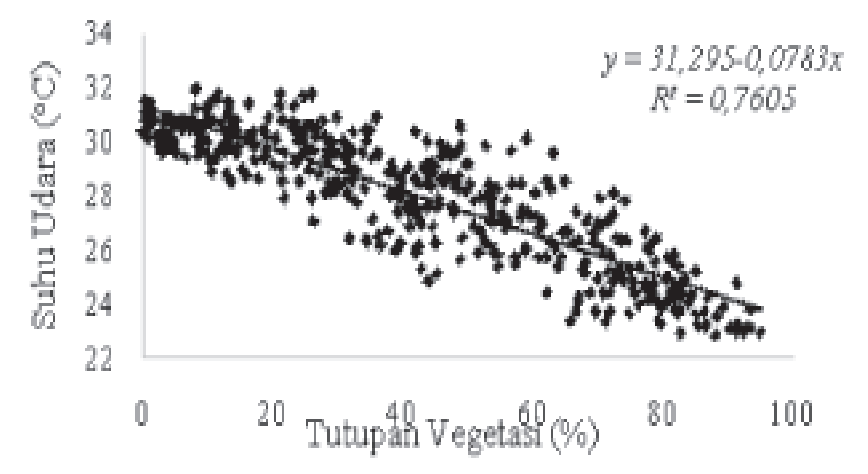

Gambar 9. Grafik Scatterplot Tahun 2015

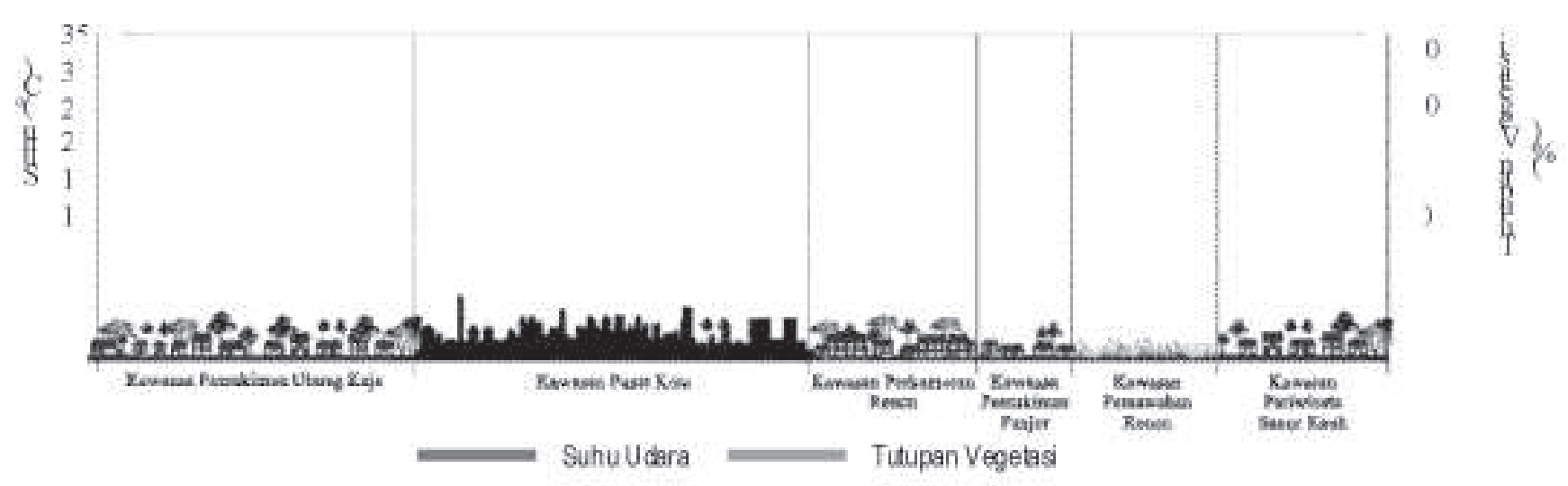

Gambar 8. Grafik Hubungan Tutupan Vegetasi terhadap Suhu Permukaan Lahan dan Suhu Udara 


\subsection{Upaya dalam Menyikapi Peningkatan Suhu} Udara Kota Denpasar

Upaya yang direkomendasikan dalam menyikapi peningkatan suhu udara yang terjadi di Kota Denpasar adalah dengan meningkatkan jumlah RTH kota. Berdasarkan hasil klasifikasi nilai tutupan vegetasi dan suhu udara diperoleh tiga kategori daerah rekomendasi prioritas pengembangan RTH yaitu prioritas tinggi, sedang dan rendah. Prioritas tinggi yaitu daerah-daerah yang memiliki tutupan vegetasi $<30 \%$ dengan suhu udara $>30{ }^{\circ} \mathrm{C}$ serta mengalami peningkatan suhu udara $>3{ }^{\circ} \mathrm{C}$. Prioritas sedang dengan tutupan vegetasi $30 \%-50 \%$, suhu udara $28^{\circ} \mathrm{C}-30{ }^{\circ} \mathrm{C}$ serta mengalami peningkatan suhu $0{ }^{\circ} \mathrm{C}-3{ }^{\circ} \mathrm{C}$. Prioritas rendah dengan tutupan vegetasi $>50 \%$, suhu udara $<28{ }^{\circ} \mathrm{C}$ serta mengalami peningkatan suhu $<0{ }^{\circ} \mathrm{C}$. Pengembangan bentuk RTH pada daerah-daerah tersebut dapat menyesuaikan dengan kondisi karakteristik penggunaan lahan kota. Peta sebaran daerah rekomendasi prioritas pengembangan RTH Kota Denpasar disajikan pada Gambar 10.

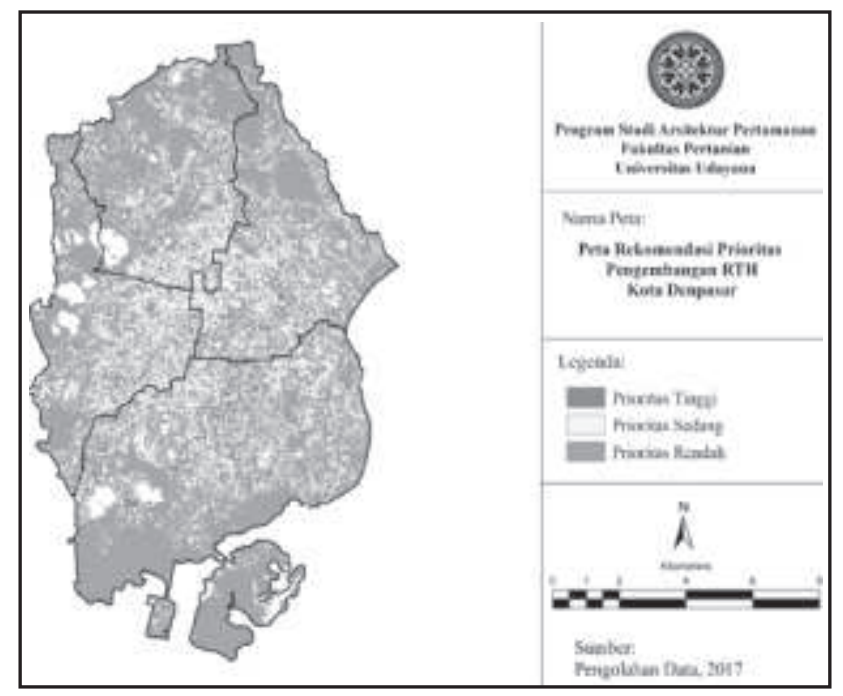

Gambar 10. Peta Rekomendasi Prioritas Pengembangan RTH Kota Denpasar

\section{SIMPULAN DAN SARAN}

\subsection{Simpulan}

1. Wilayah Kota Denpasar pada tahun 2003, 2009 dan 2015 mengalami penurunan persentase lahan tutupan vegetasi sebesar $7,65 \%$.
2. Pada periode yang sama Kota Denpasar juga mengalami kenaikan suhu udara yaitu sebesar $1,7^{\circ} \mathrm{C}$.

3. Korelasi antara tutupan vegetasi dan suhu udara Kota Denpasar diproyeksikan pada persamaan $y=31,295-0,078 x$. Setiap adanya penurunan $1 \%$ tutupan vegetasi maka akan menaikkan suhu udara sebesar $0,078^{\circ} \mathrm{C}$.

\subsection{Saran}

1. Perlu dilakukan penelitian lebih lanjut tentang faktor lain yang dapat mempengaruhi perubahan suhu udara seperti polusi dan material fisik kota serta perlu diteliti lebih lanjut juga seberapa besar pengaruh faktor tersebut.

2. Kepada Pemerintah Kota Denpasar dalam menata dan mengelola ruang kota perlu mempertimbangkan agar dapat mempertahankan lahan tutupan vegetasi serta meningkatkan jumlah RTH kota melalui perencanaan pengembangan RTH untuk meningkatkan kualitas lingkungan Kota Denpasar.

\section{DAFTAR PUSTAKA}

BPS. 2003. Denpasar Dalam Angka 2003. Badan Pusat Statistik, Kota Denpasar.

2016. Denpasar Dalam Angka 2016. Badan Pusat Statistik, Kota Denpasar.

Effendy, S., Bey, A., Zain, A, F, M., Santosa, I. 2006. Peranan Ruang Terbuka Hijau dalam Mengendalikan Suhu Udara dan Urban Heat Island Wilayah JABOTABEK. J Agromet Indonesia, 20(1):23-33.

Riana, I. N., Widiastuti, W., Primayatna, I. B. G. 2014. Kajian Alih Fungsi Ruang Terbuka Hijau di Kota Denpasar. Journal of the Built Environment, 1(1):1-2.

Wijaatmaja, A.B.M., 2015. Pendekatan Perencanaan Tata Ruang Wilayah di Kota Denpasar. Tesis (tidak dipublikasi). Universitas Udayana. 